\title{
Silicone Oil and Iodine-125 Brachytherapy for Uveal Melanoma in High-Risk Patients
}

\author{
Lance J. Lyons ${ }^{1}$, Ethan D. Hinds ${ }^{1}$, Sarada Chexal ${ }^{2}$, Brian Berger ${ }^{2}$ \\ 1. Ophthalmology, University of Texas Medical Branch, Galveston, USA 2. Ophthalmology, Retina Consultants of \\ Austin, Austin, USA
}

Corresponding author: Lance J. Lyons, lancejlyons@gmail.com

\section{Abstract \\ Purpose}

Silicone oil a burgeoning adjuvant in the treatment of uveal melanoma where it is used for tissue protection during I-125 brachytherapy. While risk factors in the development of radiation retinopathy (RR) have been identified, treatment modulation for high-risk patients has largely been overlooked. We seek to expand the literature on this subject by reporting outcomes of I-125 brachytherapy with silicone oil in a high-risk population in the community setting.

\section{Methods}

Five patients with uveal melanoma and at least one risk factor for RR development underwent iodine-125 (I125) plaque brachytherapy with concurrent pars plana vitrectomy (PPV), silicone oil administration, and fine needle aspiration biopsy (FNAB). Plaque and silicone oil removal were performed after seven days. Minimum follow-up was 12 months.

\section{Results}

Follow-up ranged from 12 to 56 months. Macular radiation doses ranged from 12.55 to $141.5 \mathrm{~Gy}$; the two eyes with the largest doses developed RR at 34 and 15 months as well as neovascular glaucoma (NVG). Surgical complications included one rhegmatogenous retinal detachment (RD) and an intra-operative vitreous hemorrhage with post-operative hyphema requiring additional intervention.

\section{Conclusion}

RR may be attenuated by silicone oil administration in patients with some risk factors. In tumors farther from the macula, this benefit is more readily apparent. Tumors located more posteriorly may not benefit from silicone oil administration considering postoperative complications and operating time. Patient demographics, tumor characteristics, and anticipated macular radiation dosage may help determine which patients can benefit from silicone oil and identify patient risks for adverse outcomes.

Received 06/25/2019

Review began 06/27/2019

Review ended 07/22/2019

Published 07/29/2019

\section{() Copyright 2019}

Lyons et al. This is an open access article distributed under the terms of the Creative Commons Attribution License CC-BY 3.0., which permits unrestricted use, distribution, and reproduction in any medium, provided the original author and source are credited.
Categories: Ophthalmology, Radiation Oncology, Oncology

Keywords: choroidal melanoma, plaque brachytherapy, radiation retinopathy, silicone oil

\section{Introduction}

The most common cause of primary intraocular cancer in adults is melanoma arising from the choroid and ciliary body [1]. The standard of care for small and medium-sized tumors is iodine-125 plaque (I-125) brachyotherapy, as established by the collaborative ocular melanoma study (COMS) [2-4]. However, patients generally lose two lines of visual acuity per year and nearly $45 \%$ develop acuity $\leqslant 20 / 200$ within three years [5]. Side effects typically occur one and a half to two years post-treatment, though they may occur up to five years post-treatment $[6,7]$. Cystoid macular edema, macula ischemia, and chorioretinal atrophy constitute radiation retinopathy (RR), appearing in up to $43 \%$ of patients within five years of receiving brachytherapy $[6,8]$. In the COMS literature, photographic and angiographic studies confirmed radiation-associated macular pathology in up to $75 \%$ of patients in five years post-brachyotherapy. The high rate of adverse events indicates a need for improvement of radioactive brachytherapy for uveal melanoma.

Since 2010, various fluids have been considered to reduce radiation exposure to healthy tissues [9]. Of the four intraocular vitreous substitutes tested, 1000 and 5000-centistoke (cSt) silicone oil (polydimethyl-nsiloxane) were identified as candidates for further study due to the reduction of radiation penetrance by $48 \%$ and $47 \%$ under vitro and ex vivo conditions, respectively. A monte carlo simulation projected up to $57 \%$ reduction of radiation exposure to vital ocular structures. Ahuja et el. confirmed reductions of $65 \%$ in dose delivery under in vitro conditions, which prompted them to test the procedure in three patients [10]. Absence of RR up to to 24 months suggested that silicone oil may improve outcomes in clinical settings and opened the door to more robust studies. 
In two case-controlled studies of 20 patients, McCannel et al. elucidated silicone oil's potential role in treatment of uveal melanoma [11,12]. The 2014 study concluded that the experimental group yielded fewer abnormal maculas, lower central macular thickness on optical coherence tomography (OCT), and better final visual acuity. Two years later, they found that radiation attenuation from silicone oil significantly improved visual acuity.

Despite the recent success of silicone oil administration, high-risk patients have been overlooked in the literature. Identified risk factors for RR include tumors size, total radiation dose, proximity of tumor to affected structures, and systemic conditions such as diabetes mellitus [8,12-14]. Given the potential benefits of silicone oil administration, we sought to study outcomes in a patient sample otherwise considered as high-risk in a community setting, which may more closely reflect the population.

\section{Materials And Methods}

Inclusion criteria for patients were diagnosis of uveal melanoma with at least one known risk factor, including age over 60, systemic disease (hypertension and/or diabetes), or high macular radiation dose. Minimum follow-up was 12 months.

Five patients with medium to large sized melanomas (as defined by COMS guidelines) received I-125 plaque brachytherapy implanted by the same surgeon (BB) from 2011 to 2016 [15]. Dosimetry was 85 gray (Gy) to tumor apices, as determined by the Eye Physics ${ }^{\mathrm{TM}}$ plaque simulator treatment plan. A 23-gauge trocar system established access to the posterior segment of the eye $4 \mathrm{~mm}$ from the limbus. Tumor location was confirmed using indirect ophthalmoscopy and transillumination. Fine needle aspiration biopsy (FNAB) was performed via a transcleral or transvitreal approach for cytopathology and molecular analysis. Core and peripheral vitrectomy were performed, followed by administration of either 1000 or 500 cSt silicone oil into the posterior segment. When necessary, extraocular muscles were displaced to achieve tumor coverage. An Eye Physics ${ }^{\mathrm{TM}}$ plaque was then secured to the sclera. After seven days, the plaque and silicone oil were removed in a single procedure. When possible, barrier laser photocoagulation was applied to the tumor circumference during plaque removal. FNAB samples were sent for classification and risk stratification analysis. RR was determined clinically during follow-up.

\section{Results}

Clinical charts were reviewed for patient demographics, tumor location and grade, and surgical details of brachytherapy (Table 1). Outcomes including eye retention, visual acuity, RR presence and time to development, toxicity, metastasis, and surgical complications were recorded (Table 2).

\begin{tabular}{|c|c|c|c|c|c|c|c|c|}
\hline Patient & Age & Gender & PMH & Tumor Size (mm) & Tumor Location & $\begin{array}{l}\text { Macular } \\
\text { Dose }\end{array}$ & $\begin{array}{l}\text { Distance from plaque to } \\
\text { macula }\end{array}$ & $\begin{array}{l}\text { Total Follow } \\
\text { Up }\end{array}$ \\
\hline 1 & 60 & Male & $\begin{array}{l}\text { DM, } \\
\text { HTN }\end{array}$ & $\begin{array}{l}\text { H } 11.02 \text { L } 9.7 \text { W } \\
9.41\end{array}$ & $\begin{array}{l}\text { Encroaching on macula } \\
\text { inferotemporally }\end{array}$ & 141.5 Gy & $8.8 \mathrm{~mm}$ & 56 months \\
\hline 2 & 61 & Male & $\begin{array}{l}\text { DM, } \\
\text { HTN }\end{array}$ & $\begin{array}{l}\text { H } 6.2 \text { L } 12.0 \mathrm{~W} \\
12.0\end{array}$ & Inferotemporal & 21.25 Gy & $16.77 \mathrm{~mm}$ & 45 months \\
\hline 3 & 84 & Female & HTN & $\begin{array}{l}\text { H } 3.18 \text { L } 12.92 \\
\text { W } 8.87\end{array}$ & Nasal & 12.55 Gy & $17.17 \mathrm{~mm}$ & 26 months \\
\hline 4 & 68 & Male & DM & $\begin{array}{l}\text { H } 7.3 \text { L } 13.6 \text { W } \\
14.5\end{array}$ & Temporal & 43.17 Gy & $14.08 \mathrm{~mm}$ & 12 months \\
\hline 5 & 39 & Female & None & $\begin{array}{l}\text { H } 5.6 \text { L } 11.44 \text { W } \\
10.62\end{array}$ & At superior macula & 118.5 Gy & $6.9 \mathrm{~mm}$ & 51 months \\
\hline $\begin{array}{l}\text { TABLE } \\
\text { Abbrevia } \\
\text { millimeter }\end{array}$ & . & $4-6$ & Pa & tory. H- & igth. W- v & cula & ses ar & Tim \\
\hline
\end{tabular}




\section{Cureus}

\begin{tabular}{|c|c|c|c|c|}
\hline Patient & $\begin{array}{l}\text { Visual acuity pre-op, post-op } 1 \text { year, } \\
2 \text { years, } 3 \text { years }\end{array}$ & $\begin{array}{l}\text { RR, Time to } \\
\text { Development }\end{array}$ & $\begin{array}{l}\text { Other Toxicity or } \\
\text { Complication }\end{array}$ & Surgical Complications \\
\hline 1 & 20/60 +2, HM, LP, HM & $\begin{array}{l}\text { Yes, } 34 \text { months, with } \\
\text { subsequent NVG }\end{array}$ & $\begin{array}{l}\text { Optic atrophy, choroidal } \\
\text { atrophy }\end{array}$ & $\begin{array}{l}\text { Vitreous hemorrhage intra-op. Post-op } \\
\text { hyphema }\end{array}$ \\
\hline 2 & $20 / 20,20 / 20-1,20 / 40-2,20 / 30$ & No & None & $\begin{array}{l}\text { Rhegmatogenous } \mathrm{RD} \text { (treated with full } \\
\text { recovery of vision) }\end{array}$ \\
\hline 3 & $20 / 40+1,20 / 30-2,20 / 30-1, N A$ & No & None & \\
\hline 4 & $20 / 50-1,20 / 30-2, N A, N A$ & No & None & \\
\hline 5 & 20/125, 20/60 -1, CF@6ft, LP & $\begin{array}{l}\text { Yes, } 15 \text { months, with } \\
\text { subsequent NVG }\end{array}$ & $\begin{array}{l}\text { Exudative RD, eventually } \\
\text { enucleated }\end{array}$ & \\
\hline
\end{tabular}

\section{TABLE 2: Outcome Measures}

*Abbreviations: HM- hand motion. NA- not applicable. CF- counts fingers. LP- light perception. NVG- neovascular glaucoma. RD- retinal detachment.

Patient age at the time of diagnosis ranged from 39 to 84 years (median 61 years), and all patients had at least one risk factor for RR development. Follow-up ranged from 12 to 56 months (median 45 months). FNAB was performed without complication on all specimens and sent for tumor classification. Grade $1 \mathrm{~A}$ was assigned to four out of five specimens, while Patient 3's sample was grade 2. Two patients had tumors encroaching on the macula, while one was nasal to the posterior pole and two were greater than $13 \mathrm{~mm}$ temporal to the fovea. Tumor thickness ranged from 3.18 to $11.02 \mathrm{~mm}$ (median $6.2 \mathrm{~mm}$ ).

Macular radiation dose ranged from 12.55 Gy to $141.5 \mathrm{~Gy}$ (median $43.17 \mathrm{~Gy}$ ). Patients 1 and 5 developed RR at 34 and 15 months, respectively. Their tumors were located closest to the posterior pole. Thus, they received the two highest macular doses in the group (141.5 Gy and $118.5 \mathrm{~Gy}$, respectively). Patient 1 also developed optic and choroidal atrophy secondary to radiation, while patient 5 developed extensive exudative RD. For eye salvage, Patient 5 received PPV with 360-degree retinectomy, endodrainage, endolaser, and 1000 cSt silicone oil injection at another institution.

Patients 1 and 5 developed RR and NVG. Patient 1 was treated with latanoprost and brimonidine/timolol but ultimately required tube-shunt surgery, which reduced the intraocular pressure to normal values. He retained visual acuity to hand motion. Patient 5 received intravitreal bevacizumab for iris neovascularization but was later enucleated due to pain. No patient developed melanoma recurrence, and there were no deaths attributed to tumor metastases.

Patients 1 and 2 developed surgical complications related to PPV. Patient 1 had vitreous hemorrhage during initial vitrectomy; after removal of silicone oil he had recurrent hyphema which was successfully treated with anterior chamber washout and intracameral bevacizumab. Patient 2 developed a rhegmatogenous RD three months after PPV and plaque placement. PPV, sulfur hexafluoride gas, and endolaser produced full recovery of vision.

\section{Discussion}

Our case series fills a critical gap in the available literature by describing outcomes of patients with at least one risk factor for RR, after treatment for uveal melanoma with silicone oil and I-125 plaque administration. Male gender, age greater than 60 years, and systemic diseases such as hypertension and diabetes have been linked to higher risk of developing RR [16-18]. Other risk factors include tumor thickness greater than $4 \mathrm{~mm}$ and radiation doses above 90 Gy to the macula [19]. Despite these known risk factors, the three prior clinical studies with this method have not reported patient demographics in a standardized manner. Only one study has reported systemic disease, with three out of 40 study participants having diabetes [12]. In our study, four of five patients had hypertension or diabetes (two with both conditions). Four were older than 60 years at time of diagnosis while three patients were male. Four patients also had tumors greater than $4 \mathrm{~mm}$ thick and two had radiation doses above $90 \mathrm{~Gy}$ to the macula. We hope that future studies in this burgeoning field will consider risk factors due to patient demographics, tumor characteristics, and dosimetry.

Despite the risks, only two eyes developed RR over the course of the study. Those patients had tumors located in the posterior pole and thus received the highest macular doses of radiation. Tumors located posteriorly may not receive as much macular protection as those located more peripherally due to the oil's inability to occlude radiation. Patients with macula-encroaching tumors and other risk factors for developing RR might be better served without vitrectomy and silicone oil insertion given their 
overwhelming risk for developing RR, the inability of silicone oil to block radiation to areas directly under the plaque, and the surgical complications that come with the additional procedure.

As silicone oil administration as an adjuvant to I-125 brachytherapy becomes increasingly adopted, we hope clinicians can develop an algorithm for risk stratification and prognosis. We agree with others that a preventative approach to radiation dose reduction may be an ideal approach, given that laser and intravitreal pharmacologic agents have failed to demonstrate efficacy $[11,20]$. In time, application of protective fluids such as silicone oil may become the standard during treatment of uveal melanoma.

\section{Conclusions}

RR may be attenuated by administration of silicone oil in patients with some risk factors; in tumors farther from the macula, this benefit is more readily apparent. Tumors located more posteriorly may not benefit, considering postoperative complications and operating time. Patient demographics, tumor characteristics, and anticipated macular radiation dosage may help determine who can benefit from silicone oil and patient risks for adverse outcomes.

\section{Additional Information \\ Disclosures}

Human subjects: Consent was obtained by all participants in this study. Animal subjects: All authors have confirmed that this study did not involve animal subjects or tissue. Conflicts of interest: In compliance with the ICMJE uniform disclosure form, all authors declare the following: Payment/services info: All authors have declared that no financial support was received from any organization for the submitted work. Financial relationships: All authors have declared that they have no financial relationships at present or within the previous three years with any organizations that might have an interest in the submitted work. Other relationships: All authors have declared that there are no other relationships or activities that could appear to have influenced the submitted work.

\section{Acknowledgements}

The authors would like to thank Ivana Gunderson for her assistance with this project.

\section{References}

1. Scotto J, Fraumeni JF, Lee JA: Melanomas of the eye and other noncutaneous sites: epidemiologic aspects . J Natl Cancer Inst. 1976, 56:489-491. 10.1093/jnci/56.3.489

2. Diener-West M, Earle JD, Fine SL, et al.: The COMS randomized trial of iodine 125 brachytherapy for choroidal melanoma, III: initial mortality findings. Arch Ophthalmol. 2001, 119:969-982.

3. Collaborative Ocular Melanoma Study Group: Ten-year follow-up of fellow eyes of patients enrolled in collaborative ocular melanoma study randomized trials: COMS report no 22. Ophthalmology. 2004, 5:206207. 10.1016/j.ophtha.2003.08.029

4. Collaborative Ocular Melanoma Study Group: The COMS randomized trial of Iodine 125 brachytherapy for choroidal melanoma V: twelve-year mortality rates and prognostic factors. COMS Report No. 28. Arch Ophthalmol. 2006, 124:1684. 10.1001/archopht.124.12.1684

5. Collaborative Ocular Melanoma Study Group: Collaborative ocular melanoma study (COMS) randomized trial of I-125 brachytherapy for medium choroidal melanoma. I. Visual acuity after 3 years COMS report no. 16. Ophthalmology. 2001, 108:348-366. 10.1016/S0161-6420(00)00526-1

6. Quivey JM, Char DH, Phillips TL, et al.: High intensity 125-iodine (125I) plaque treatment of uveal melanoma. Int J Radiat Oncol Biol Phys. 1993, 26:613-618. 10.1016/0360-3016(93)90277-3

7. Quivey JM, Augsburger J, Snelling L, et al.: 125I plaque therapy for uveal melanoma: Analysis of the impact of time and dose factors on local control. Cancer. 1996, 77:2356-2362. 10.1002/(SICI)10970142(19960601)77:11<2356::AID-CNCR26>3.0.CO;2-V

8. Gündüz K, Shields CL, Shields JA, et al.: Radiation retinopathy following plaque radiotherapy for posterior uveal melanoma. Arch Ophthalmol. 1999, 117:609-614. 10.1001/archopht.117.5.609

9. Oliver SC, Leu MY, DeMarco JJ, et al.: Attenuation of Iodine 125 radiation with vitreous substitutes in the treatment of uveal melanoma. Arch Ophthalmol. 2010, 128:888. 10.1001/archophthalmol.2010.117

10. Ahuja Y, Kapoor KG, Thomson RM, et al.: The effects of intraocular silicone oil placement prior to iodine 125 brachytherapy for uveal melanoma: a clinical case series. Eye. 2012, 26:1487-1489. 10.1038/eye.2012.158

11. McCannel TA and McCannel CA: Iodine 125 brachytherapy with vitrectomy and silicone oil in the treatment of uveal melanoma: 1-to-1 matched case-control series. Int J Radiat Oncol Biol Phys. 2014, 89:347-352. 10.1016/j.ijrobp.2014.02.021

12. McCannel TA, Kamrava M, Demanes J, et al.: 23-mm iodine-125 plaque for uveal melanoma: benefit of vitrectomy and silicone oil on visual acuity. Graefes Arch Clin Exp Ophthalmol. 2016, 254:2461-2467. 10.1007/s00417-016-3485-9

13. Gragoudas ES, Li W, Lane AM, et al.: Risk factors for radiation maculopathy and papillopathy after intraocular irradiation. Ophthalmology. 1999, 106:1571-1578. 10.1016/S0161-6420(99)90455-4

14. Gündüz K, Shields CL, Shields JA, et al.: Radiation complications and tumor control after plaque radiotherapy of choroidal melanoma with macular involvement. Am J Ophthalmol. 1999, 127:579-589. 10.1016/S0002-9394(98)00445-0 


\section{Cureus}

15. Diener-West M, Hawkins BS, Fine SL, et al.: Design and methods of a clinical trial for a rare condition: the ollaborative ocular melanoma study, COMS report No. 3. Control Clin Trials. 1993, 14:362-91.

10.1016/0197-2456(93)90052-F

16. Puusaari I, Heikkonen J, Kivelä T: Ocular complications after iodine brachytherapy for large uveal melanomas. Ophthalmology. 2004, 111:1768-1777. 10.1016/j.ophtha.2004.03.027

17. Jensen AW, Petersen IA, Kline RW, et al.: Radiation complications and tumor control after 125I plaque brachytherapy for ocular melanoma. Int J Radiation Oncology Biol Phys. 2005, 63:101-108. 10.1016/j.ijrobp.2005.01.022

18. Krema H, Xu W, Payne D, et al.: Factors predictive of radiations retinopathy post 125 iodine brachytherapy for uveal melanoma. Can J Ophthalmol. 2011, 46:158-163. 10.3129/110-111

19. Stack R, Elder M, Abdelaal A, et al.: New Zealand experience of I125 brachytherapy for choroidal melanoma . Clin Exp Ophthalmol. 2005, 33:490-494. 10.1111/j.1442-9071.2005.01067.x

20. Wen JC, McCannel TA: Treatment of radiation retinopathy following plaque brachytherapy for choroidal melanoma. Curr Opin Ophthalmol. 2009, 20:200-204. 10.1097/ICU.0b013e328329b62d 